\title{
THE TOXIC EFFECT OF BISPHENOL A ON ALBINO RAT TESTICLES AND THE POSSIBLE PROTECTIVE VALUE OF VITAMIN E AND MELATONIN BY
}

Somaia Rashad ${ }^{1}$, Samia Ahmed ${ }^{1}$, Mahmoud El-Sayed ${ }^{1}$, Dalia Alsaied Ahmed ${ }^{1}$

${ }^{1}$ Forensic Medicine and Clinical Toxicology Department, Faculty of Medicine, Mansoura University.

\section{ABSTRACT}

Objectives: To study bisphenol A (BPA) effect on testicular functions in adult male rats using histopathology, and biochemical assays and to investigate vitamin $\mathrm{E}$ and melatonin role on BPAinduced testicular toxicity in male rats. Methods: Adult male Sprague Dawley rats were divided into six groups $(\mathrm{n}=7)$ including negative control group, vehicle control group $(0.2 \mathrm{~mL}$ of corn oil $)$, BPA group $(50 \mathrm{mg} / \mathrm{kg})$, BPA $(50 \mathrm{mg} / \mathrm{kg})+$ vitamin E $(100 \mathrm{mg} / \mathrm{kg})$ group, BPA $(50 \mathrm{mg} / \mathrm{kg})+$ melatonin $(10$ $\mathrm{mg} / \mathrm{kg})$ group, BPA(50 mg/kg) +vitamin $\mathrm{E}(100 \mathrm{mg} / \mathrm{kg})+$ melatonin $(10 \mathrm{mg} / \mathrm{kg})$ group. All medications were given 3 days a week for 3 weeks by intraperitoneal injection except vitamin $\mathrm{E}$ were given orally by a gavage needle. Laboratory investigations (testosterone level and sperm parameters), glutathione peroxidase (GPX) activity, and histopathological examination of testis were done. Results: The BPA-treated rats showed a significant reduction in the reproductive function parameters. Furthermore, BPA induced testicular oxidative stress by decreasing GPX activity and induced significant histopathological testicular changes. Co-treatment with vitamin $\mathrm{E}$ and melatonin protected against these alterations. Conclusion: Findings from the present study confirmed that BPA caused testicular dysfunction which may be due to BPA-induced oxidative stress and showed that vitamin E and melatonin antioxidants may have a protective role on the reproductive toxicity induced by BPA in male rats.

Keywords: bisphenol A, reproductive dysfunction, oxidative stress, vitamin E, melatonin.

Corresponding author: Dr. Somaia Rashad

Email: merida_omar@yahoo.com

\section{INTRODUCTION}

$I^{n}$ n 1891, the Russian chemist Aleksandr Dianin was first convinced of Bisphenol A (BPA). It was synthesized in 1905 by Zincke through the condensation of acetone with two phenol equivalents. It is one of the most commonly used synthetic compounds in the world with an average annual growth of 13 percent and a rise of 19 percent in demand for polycarbonates in India, the greatest growth is seen in Asia and an annual production of around 5 million tons in the United States (Jalal et al., 2018).

Bisphenol-A is a monomer used for polycarbonate synthesis and as an intermediate reaction in the manufacture of epoxy resins, phenoxy resins, thermal receipts, dental sealants, medical devices, reusable food, water bottles, and drink containers, water supply pipes, flame retardants, and in the manufacture of rubber (Liu et al., 2021). Almeida et al. (2018) stated that BPA use in the fabrication of plastic food containers is currently allowed (Regulation [EU] No. 10/2011) but is forbidden based on the precautionary principle in infant feeding bottles (EU Regulation No. 321/2011).

Bisphenol-A penetrates the body through the skin, inhalation, and the digestive system (Kang et al., 2006) while inhalation exposure appears to be insignificant compared to the dietary path (Wilson et al., 2003).

BPA exposure has been linked to various toxic effects on human health, such as impaired reproduction and development, cancer, altered metabolism, and neurological and behavioral disorders (Benjamin et al., 2017). BPA acts as an endocrine disruptingchemical. Its estrogenic, anti-androgenic, and anti-thyroid activity interferes with hormonal function (Rahman and Pang, 2019).

Bisphenol A binds endocrine receptors (ERs) in the genomic pathway (nuclear) and causes their dimerization. Subsequently, either directly or indirectly, ER dimers stick to DNA 
by binding to other transcription factors, including protein 1 specificity and activator protein 1. BPA can also affect cell functions by binding membrane-bound receptors via the non-genomic pathway, leading to kinase signaling pathway activation (Shanle and $\mathrm{Xu}$, 2011). The membrane-bound receptor works with G-protein-coupled receptors (GPCRs) during these signaling cascades and can trigger rapid estrogenic signaling through phosphatidylinositol 3-kinase (PI3KK) and mitogen-activated protein kinase (MAPK) activation (Fuentes and Silveyra, 2019).

Bisphenol A's reproductive toxicity has been caused by the widespread use of plastic products. Therefore, humans are frequently subjected to BPA in their everyday lives. Measurable BPA levels have been identified by the U.S. Center for Disease Control and Prevention (CDC) in urine samples of $90 \%$ of the U.S. population (Lehmler et al., 2018). BPA, which influences male fertility, is a wellknown endocrine disruptor. However, it is still important to establish the mechanism by which BPA affects spermatogenesis (Liu et al., 2021).

Studies on human subjects and animals have consistently shown a correlation between exposure to BPA and the reproductive system, such as decreased fertility, impaired sperm function, low sperm count, and increased morphological sperm abnormalities (Pan et al., 2020). Leydig cell growth and function and related reproductive disorders such as testicular dysgenesis, delayed puberty, and subfertility/infertility is associated with BPA exposure (Li et al., 2020).

Anti-apoptotic pathways Inhibition such as Bcl-2 and activation of pro-apoptotic signaling (MAPK, Fas/FasL, Caspase 3 and 9, Bax, etc.), increased reactive oxygen species, decreased proliferation, and increased apoptosis of male gametes is associated with BPA exposure (Pallotti et al., 2020).

The toxic effects of BPA on different tissues are mainly mediated by increased oxidative stress associated with increased toxic free radical production (Rahman et al., 2016). Cellular oxidative homeostasis is disrupted by BPA, which then predisposes to apoptosis leading to cell death (Tavakkoli et al., 2020).

Oxidative stress can be defined as an imbalance between the production of reactive oxygen species (ROS) and antioxidant defenses, resulting in oxidative damage (Ratliff et al., 2016). The mitochondria have been recognized as an important intracellular source of ROS and nitrogen species generation and so defective mitochondria have been associated with various pathological conditions (OleaHerrero et al., 2014).

Antioxidants are exogenous or endogenous molecules that alleviate any sort of oxidative/nitrosative stress. From directly scavenging free radicals to increasing antioxidant defenses (Kurutas, 2016). Antioxidants protect cells from cellular oxidation reactions caused by free radicals induced by BPA exposure and so prevent the destruction of DNA, RNA, and proteins (Nur et al., 2019). Antioxidants are mainly classified into two major groups, enzymatic (e.g., superoxide dismutase, catalase,...) and nonenzymatic (e.g., vitamin E, vitamin A, vitamin C, flavonoids, carotenoids, glutathione, melatonin).

Vitamin $\mathrm{E}$ is the generic name for tocopherols, which are a class of chemical phenolic compounds (Gulcin, 2020). Vitamin E is a fat-soluble vitamin that has antioxidant properties to protect body cells, from freeradical and ROS damage. They are the bestknown and most widely used antioxidants. The first line of cell membranes protection against oxidation is vitamin E (Niki, 2014).

Melatonin is a potent antioxidant that is endogenously secreted (Gunata et al., 2020). Melatonin is an important free-radical scavenger and antioxidant that can directly scavenge excessive ROS and can enhance the function of the antioxidant enzyme system (Cen et al., 2020).

The mitochondria have been identified as a target for melatonin actions, and melatonin protects against mitochondrial oxidative damage under various pathological conditions (Chen et al., 2015). Reports also showed that melatonin interacts with lipid bilayers, reduces lipid peroxidation, and stabilizes the internal 
mitochondrial membrane, thereby improving the activity of the electron transport chain (ETC) (Reiter et al., 2014).

The present study aims to evaluate bisphenol A-induced laboratory and histopathological alterations in the reproductive organs (testicles) of albino rats and the value of melatonin and vitamin $\mathrm{E}$ in the protection against BPA-induced testicular toxicity.

\section{MATERIAL AND METHODS}

This research was authorized by the Institutional Research Board of the Mansoura Faculty of Medicine, Mansoura University (MS. 19.09.800.R1).

\section{- Chemicals:}

Bisphenol A: (>99\%, liquid 50gm bottle).

Melatonin: powder, $250 \mathrm{mg}$ in a glass bottle, dissolved in ethanol: $50 \mathrm{mg} / \mathrm{mL}$.

Vitamin E: $\alpha$-Tocopherol the active liquid form of Vit $\mathrm{E}$ in a glass bottle contains $100 \mathrm{~g}$.

Corn oil: liquid form, $2.5 \mathrm{~L}$ in a bottle.

All reagents were purchased from Sigma Aldrich $^{\mathrm{TM}}$ (Saint Louis, MO, USA).

\section{- Animals:}

This study was conducted on forty-two male Sprague Dawley rats, 8 weeks old. Their weights ranged from 200-220 g. They were obtained from the animal house, Faculty of Pharmacy, Mansoura University, Egypt.

Under normal laboratory conditions, including appropriate temperature $\left(22 \pm 2^{\circ} \mathrm{C}\right)$, good lighting (12 hours light/dark cycle), and good aeration, the animals were housed in clean cages. A normal laboratory diet and tap water was given to them.

\section{- Instruments:}

Standard light microscopy (binocular, OPTICA) attached to a digital camera (Canon 5 megapixels, 3.2x optical zoom). Needles, syringes, scalpels, test tubes, and glass slides were purchased from the animal house, Faculty of Pharmacy.

\section{- Experimental Design:}

This experimental work was conducted in the Faculty of Pharmacy, Mansoura University.

The rats were randomly divided into six groups; each group contains seven rats as follow:

Group 1: rats received ordinary food and water and serve as a negative control group.

Group 2: rats received $0.2 \mathrm{~mL}$ of corn oil (the vehicle of BPA) by the intraperitoneal route and serve as the vehicle control group.

Group 3: rats were given BPA dissolved in corn oil at $50 \mathrm{mg} / \mathrm{kg}$ body weight 3 days a week for 3 weeks by intraperitoneal injection (Othman et al., 2014).

Group 4: rats were treated with vitamin E 100 $\mathrm{mg} / \mathrm{kg}$ body weight body orally by a gavage needle followed by BPA $50 \mathrm{mg} / \mathrm{kg}$ dissolved in corn oil by intraperitoneal injection 3 days a week for 3 weeks (Amraoui et al., 2018).

Group 5: rats were given melatonin $10 \mathrm{mg} / \mathrm{kg}$ body weight by intraperitoneal route followed by BPA $50 \mathrm{mg} / \mathrm{kg}$ body weight dissolved in corn oil by intraperitoneal injection 3 days a week for 3 weeks (Othman et al., 2014).

Group 6: rats were treated with vitamin E 100 $\mathrm{mg} / \mathrm{kg}$ body weight body orally by a gavage needle and melatonin $10 \mathrm{mg} / \mathrm{kg}$ body weight by intraperitoneal route followed by BPA 50 $\mathrm{mg} / \mathrm{kg}$ body weight dissolved in corn oil by intraperitoneal injection 3 days a week for 3 weeks (Amraoui et al., 2018).

Sperm was obtained at the end of the experiment as follows; the epididymis of both testes was separated and cut free of fat and put at $37^{\circ} \mathrm{C}$ in physiological saline. In the proximal and distal cauda of each epididymis, there will be three deep cuts. The tissue is removed after 5 minutes of incubation at $37^{\circ} \mathrm{C}$, and the sperm suspensions are gently combined and preserved at $37^{\circ} \mathrm{C}$. Also, rats' blood will be obtained, left to clot and unhaemolysed serum will be separated for serum testosterone, male adult rats will be sacrificed; testicles will be removed and examined.

Assessment of the effects of bisphenol A, Vit E, and melatonin on testicular tissue was done through laboratory investigations (testosterone level \& sperm parameters), assessment of Glutathione Peroxidase (GPX) activity, and histopathological examination of the testis.

\section{Testicular function assessment:}

Measurements of serum testosterone levels: The serum testosterone level was estimated by a commercially available radioimmunoassay kit 
(rat testosterone RIA kit, IMMUNOTECH, USA).

Sperm count: The epididymal sperm samples were collected in physiological saline by separating known weights of cauda epididymis in the ratio of $1: 10$ weight by volume. The suspension was filtered using an $80 \mu \mathrm{m}$ stainless mesh. Using the improved Neubauer2.2. cytometer, the epididymal sperm count was obtained by cytometry and was represented as a million/mL suspension.

Sperm morphology: With $10 \mu \mathrm{l}$ of eosinnigrosin dye, $10 \mu \mathrm{l}$ of sperm suspension was applied and a dense smear was made on the slides. The eosin stain is excluded from normal live sperm and appears white, while "dead" sperm takes up eosin and appears pinkish. The percentage of irregular sperm morphology was measured.

Sperm motility: Sperm motility was identified using the Sönmez et al (2005) method. By using a pipette, fluid was taken from the caudal epididymis and diluted with a $2 \mathrm{~mL}$ Tris buffer solution. The system was pre-warmed $\left(35^{\circ} \mathrm{C}\right)$, three separate fields were tested, and the mean value was reported as the final motility score.

Assessment of Glutathione peroxidase (GSH Px) activity: The activity of glutathione peroxidase (GSH-Px) was assessed as described by Paglia and Valentine (1967). GSSG derived from GSH was calculated in this method due to GSH-Px in the presence of NADPH and GSHR. GSH-Px activity was measured from the change in NADPH concentration with time using $\square=6270 \mathrm{M}^{-1} \mathrm{~cm}^{-1}$.

\section{Histopathological evaluation:}

Both testicles were cut, soaked overnight in the Bouin fixative, and embedded in paraffin. Sections (5 um in thickness) were cut from the top to the end of the testis at intervals of $200 \mathrm{um}$ and then stained with hematoxylin and eosin. With a standard light microscope, all parts were histopathologically examined. A digital camera captured the images.

Statistical analysis:

The collected data were coded, processed, and analyzed using the Statistical Package of Social Science (SPSS) program for windows (version 16). Quantitative data were presented as mean \pm standard deviation (SD). The normality of data was tested using Kolmogrove -Smirnoff test. The Independent ttest was used on comparing two groups. For comparing more than two groups, a one-way ANOVA test was used. P-value $\leq 0.05$ was considered to be significant in two-sided statistical tests. If $\mathrm{p}$-value $\leq 0.05$, we reject the null hypothesis $(\mathrm{H} 0)$ and conclude that there is a significant difference between groups.

\section{RESULTS}

No toxic manifestations or mortality among the studied animals were reported during the experimental period.

The effect of BPA on albino rats' reproductive function parameters is illustrated in table (1). The reproductive functions in the BPA group were significantly reduced compared to the negative and vehicle control groups $(\mathrm{p}<0.001)$. Sperm count, sperm motility, serum testosterone level, and glutathione peroxidase (GPX) were significantly decreased while abnormal sperm morphology was significantly increased compared to negative and vehicle control groups.

Table (1): The effect of BPA on albino rats' reproductive function parameters and glutathione peroxidase activity compared to control groups.

\begin{tabular}{lllll}
\hline $\begin{array}{l}\text { Reproductive function parameters } \\
\text { Mean } \pm \text { SD }\end{array}$ & $\begin{array}{l}\text { Negative control } \\
\text { group }(\mathbf{n}=7)\end{array}$ & $\begin{array}{l}\text { Vehicle control } \\
\text { group }(\mathbf{n}=7)\end{array}$ & $\begin{array}{l}\text { BPA group } \\
(\mathbf{n}=7)\end{array}$ & P value \\
\hline Abnormal sperm morphology $(\%)$ & $2.3 \pm 0.5^{\mathrm{c}}$ & $2.7 \pm 0.8^{\mathrm{c}}$ & $19.1 \pm 4.4^{\mathrm{a}, \mathrm{b}}$ & $<0.001^{*}$ \\
\hline Sperm count $\left(10^{6} / \mathrm{ml}\right)$ & $144.1 \pm 12.3^{\mathrm{c}}$ & $135.0 \pm 10.3^{\mathrm{c}}$ & $60.8 \pm 10.5^{\mathrm{a}, \mathrm{b}}$ & $<0.001^{*}$ \\
\hline Sperm motility $(\%)$ & $92.9 \pm 2.7^{\mathrm{c}}$ & $92.1 \pm 2.7^{\mathrm{c}}$ & $52.1 \pm 4.9^{\mathrm{a}, \mathrm{b}}$ & $<0.001^{*}$ \\
\hline Serum testosterone $(\mathrm{ng} / \mathrm{dl})$ & $255.8 \pm 25.2^{\mathrm{c}}$ & $219.7 \pm 25.4^{\mathrm{c}}$ & $73.8 \pm 12.3^{\mathrm{a}, \mathrm{b}}$ & $<0.001^{*}$ \\
\hline Glutathione Peroxidase $(\mathrm{GPX})(\mathrm{U} / \mathrm{g})$ & $134.2 \pm 13.3^{\mathrm{c}}$ & $127.3 \pm 11.4^{\mathrm{c}}$ & $54.6 \pm 12.1^{\mathrm{a}, \mathrm{b}}$ & $<0.001^{*}$ \\
\hline * Significant if $P \leq 0.05$ & $\begin{array}{l}\text { a significant difference versus the negative control group } \\
\text { c significant difference versus BPA group }\end{array}$
\end{tabular}


Microscopic examination of $\mathrm{H} \& \mathrm{E}$ stained testicular sections from the negative control group (Fig. 1 A, B) and vehicle control group (Fig. 1 C, D) showing regular crossly sectioned seminiferous tubules lined with germinal epithelium, several layers of spermatocytes, spermatids hanged to Sertoli cells, and spermatozoa in the lumen. Narrow interstitial space seen in between seminiferous tubules consists of loose areolar connective tissue containing the interstitial cells (Leydig cells). Testicular sections from the group received BPA showing widened lumen of some crossly sectioned seminiferous tubules free from spermatozoa (Fig. 1 E), the vacuolated epithelium (Fig. 1 F), separated epithelial lining from the basement membrane, and congested blood vessels (Fig. 1 G, H).

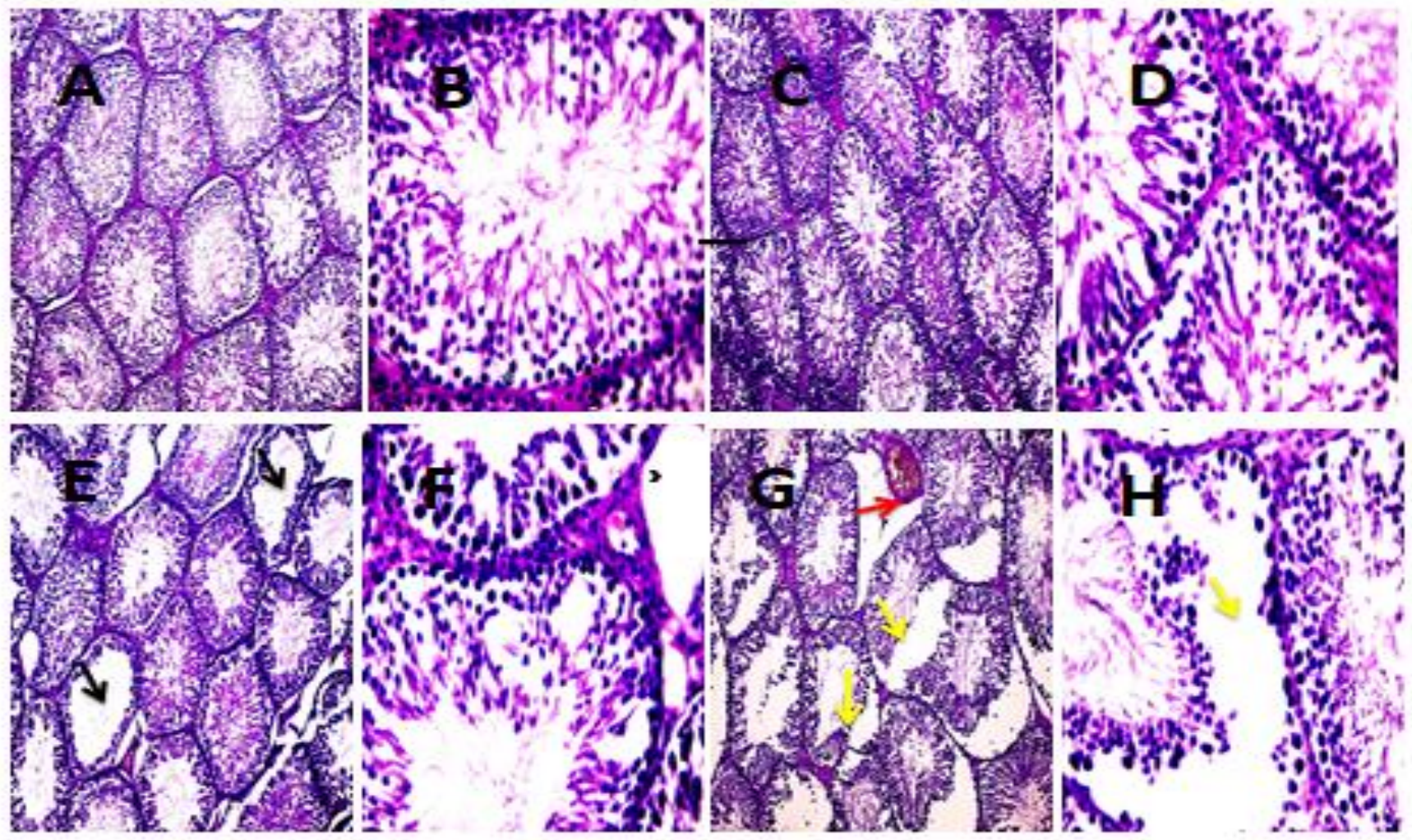

Figure 1: Microscopic pictures of $H \& E$ stained testicular sections from negative control group (A\&B) and vehicle control group $(C \& D)$ showing regular crossly sectioned seminiferous tubules lined with germinal epithelium, several layers of spermatocytes, spermatids hanged to Sertoli cells, and spermatozoa in the lumen. Narrow interstitial space seen in between seminiferous tubules consists of loose areolar connective tissue containing the interstitial cells (Leydig cells). Testicular sections from the group received BPA showing widened lumen of some crossly sectioned seminiferous tubules (black arrows) free from spermatozoa $(E)$, vacuolated epithelium (arrowheads) $(F)$, separated epithelial lining from the basement membrane (yellow arrows), and congested blood vessel (red arrow) $(G \& H)$. X:100 (A, C, E, G) X:400 bar $50(B, D, F, H)$.

The effect of vitamin E, melatonin, and combined vitamin $\mathrm{E}+$ melatonin antioxidants on BPA induced reproductive dysfunctions, are showed in the table (2). Reproductive function parameters and glutathione peroxidase activity were significantly improved after administration of vitamin $\mathrm{E}$ and melatonin antioxidants compared to the BPA group. 
Table (2): Studying the effect of antioxidants (vitamin E, melatonin, and vitamin E + melatonin) on BPA induced reproductive dysfunctions:

\begin{tabular}{|c|c|c|c|c|c|}
\hline $\begin{array}{l}\text { Reproductive function parameters } \\
\text { Mean } \pm \text { SD }\end{array}$ & $\begin{array}{l}\text { BPA } \\
(n=7)\end{array}$ & $\begin{array}{l}\text { BPA+vitamin E } \\
(n=7)\end{array}$ & $\begin{array}{l}\text { BPA + Melatonin } \\
(n=7)\end{array}$ & $\begin{array}{l}\text { BPA+vit E + } \\
\text { Melatonin }(n=7)\end{array}$ & P value * \\
\hline Abnormal sperm morphology (\%) & $19.1 \pm 4.4$ & $7.7 \pm 1.7$ & $13.71 \pm 2.3$ & $5.6 \pm 1.0$ & $\begin{array}{l}\mathrm{P} 1<0.001 \\
\mathrm{P} 2=0.013 \\
\mathrm{P} 3<0.001\end{array}$ \\
\hline Sperm count $\left(10^{6} / \mathrm{ml}\right)$ & $60.8 \pm 10.5$ & $100.2 \pm 8.8$ & $82.3 \pm 9.9$ & $116.9 \pm 13.7$ & $\begin{array}{l}\mathrm{P} 1<0.001 \\
\mathrm{P} 2=0.002 \\
\mathrm{P} 3<0.001\end{array}$ \\
\hline Serum testosterone (ng / dl) & $73.8 \pm 12.3$ & $155.2 \pm 19.6$ & $138.0 \pm 21.1$ & $189.4 \pm 23.8$ & $\begin{array}{l}\mathrm{P} 1<0.001 \\
\mathrm{P} 2<0.001 \\
\mathrm{P} 3<0.001\end{array}$ \\
\hline Glutathione Peroxidase (GPX) (U/g) & $54.6 \pm 12.1$ & $82.8 \pm 11.3$ & $71.5 \pm 10.5$ & $96.3 \pm 11.3$ & $\begin{array}{l}\mathrm{P} 1=0.001 \\
\mathrm{P} 2=0.016 \\
\mathrm{P} 3<0.001\end{array}$ \\
\hline
\end{tabular}

* Significant if $P \leq 0.05$ P1: for comparison between BPA + vitamin E group and BPA group P2: for comparison between $\mathrm{BPA}+$ Melatonin group and BPA group P3: for comparison between BPA + Vit E + Melatonin group and BPA group.

Microscopic pictures of $\mathrm{H} \& \mathrm{E}$ stained testicular sections from the treated group with melatonin (Fig. 2 A, B) showing moderate interstitial edema and vacuolated epithelial lining. Testicular sections from the group received vitamin $\mathrm{E}$ showing mild interstitial edema, widened lumen of a few crossly sectioned seminiferous tubules free from spermatozoa and vacuolated epithelial lining (Fig. 2 C, D). Testicular sections from the group received melatonin+vitamin $\mathrm{E}$ showing an improved histological picture of seminiferous tubules with narrowed interstitial space in between (Fig. 2 E, F).
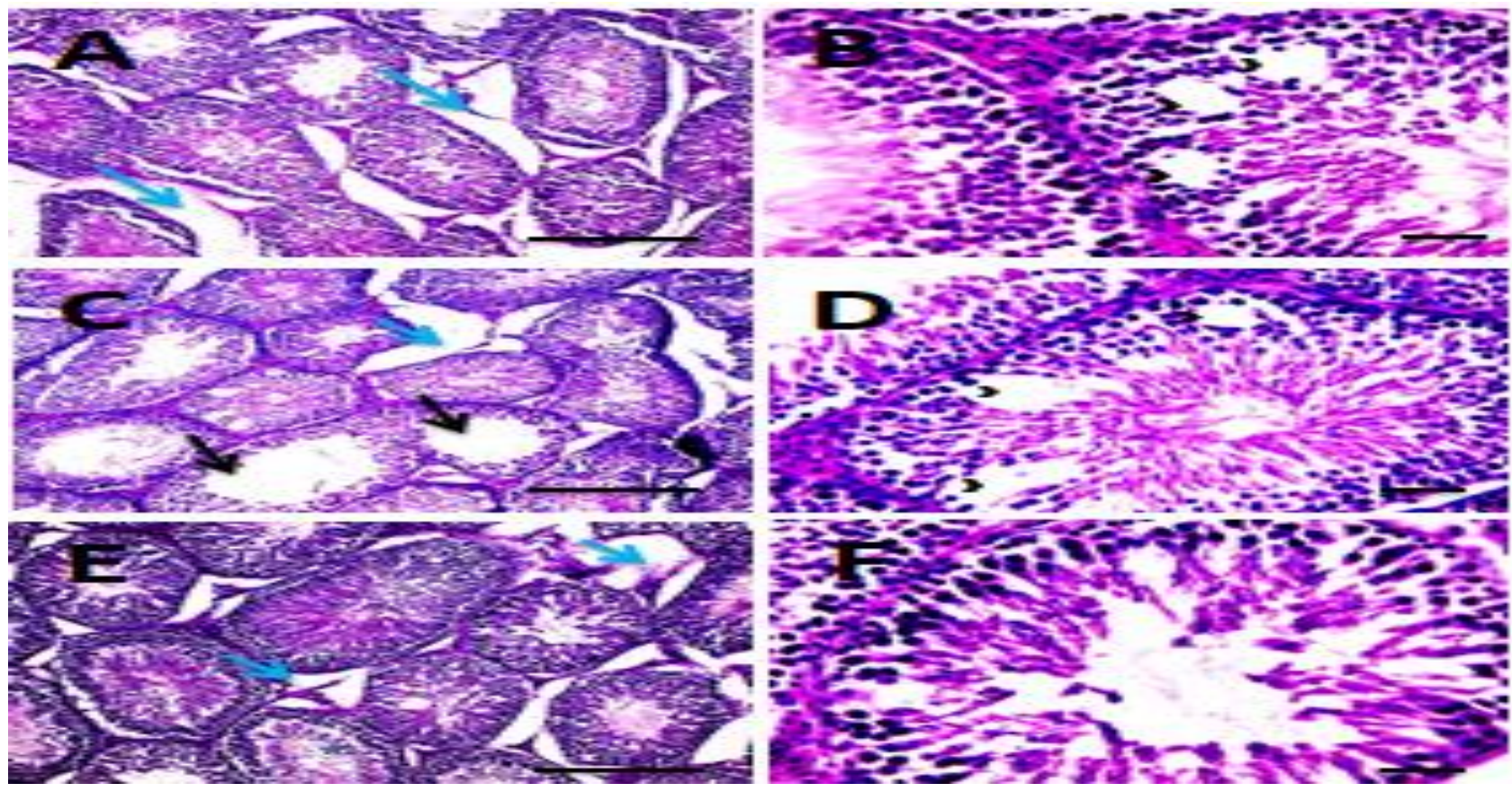

Figure 2: Microscopic pictures of $H \& E$ stained testicular sections from the treated group with melatonin $(A, B)$ showing moderate interstitial edema (blue arrows) and vacuolated epithelial lining (arrowheads). Testicular sections from the group received vitamin $E$ showing mild interstitial edema (blue arrows), widened lumen of few crossly sectioned seminiferous tubules (black arrows) free from spermatozoa, and vacuolated epithelial lining (arrowheads) $(C, D)$. Testicular sections from the group received melatonin+vitamin $E$ showing an improved histological picture of seminiferous tubules with narrowed interstitial space in between (blue arrows) $(E \& F)$. X:100 bar $100(A, C, E)$ and X:400 bar 50 (B, D, F). 
Reproductive function parameters improved in animal groups receiving antioxidants together with BPA. Abnormal sperm morphology decreased significantly in BPA +melatonin+vitamin E (5.6\%) then $\mathrm{BPA}+$ vitamin $\mathrm{E}(7.7 \%)$ then $\mathrm{BPA}$ +melatonin (13.7\%) (figure 3). Figure (4) shows the mean effect of different antioxidants on albino rats' sperm count; BPA +melatonin+vitamin $\mathrm{E}$ showed the highest sperm count $116.9\left(10^{6} /\right.$ $\mathrm{ml})$ then BPA + vitamin E $100.2\left(10^{6} / \mathrm{ml}\right)$ then BPA +melatonin $82.3\left(10^{6} / \mathrm{ml}\right)$. Sperm

Abnormal Sperm Morphology (\%)

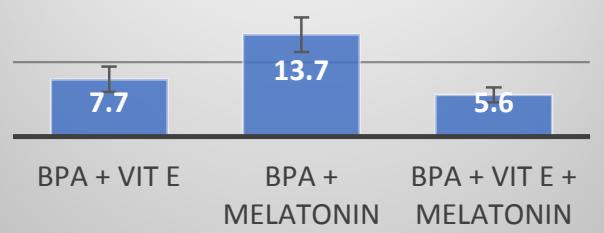

Figure 3. Mean effect of different antioxidants on albino rats' sperm morphology

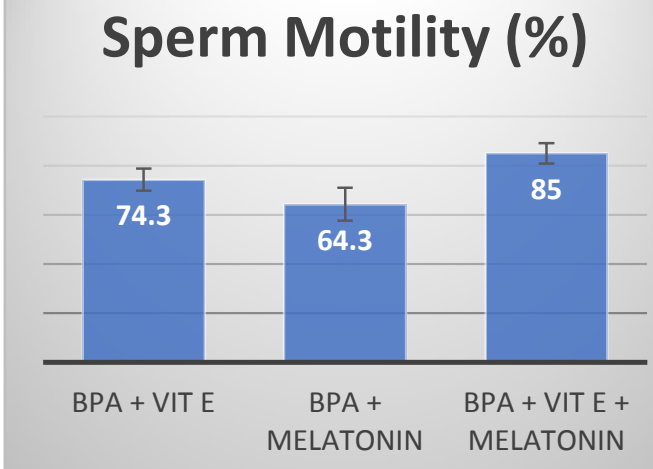

Figure 5. Mean effect of different antioxidants on albino rats' sperm motility motility was improved significantly in BPA +melatonin+vitamin $\mathrm{E}(85 \%)$ then $\mathrm{BPA}+$ vitamin $\mathrm{E}(74.3 \%)$ then $\mathrm{BPA}+$ melatonin $(64.3$ $\%$ ) (figure 5). Serum testosterone level increased significantly in in BPA +melatonin+vitamin E $(189.4 \mathrm{ng} / \mathrm{dl})$ then BPA + vitamin E (155.2 ng / dl) then BPA +melatonin (138 ng / dl) (figure 6). Glutathione Peroxidase (GPX) activity was (96.3 U/ g) in BPA +melatonin+vitamin E, (82.8 U/ g) in $\mathrm{BPA}+$ vitamin $\mathrm{E}$ and $(71.5 \mathrm{U} / \mathrm{g})$ in $\mathrm{BPA}$ +melatonin (figure 7).

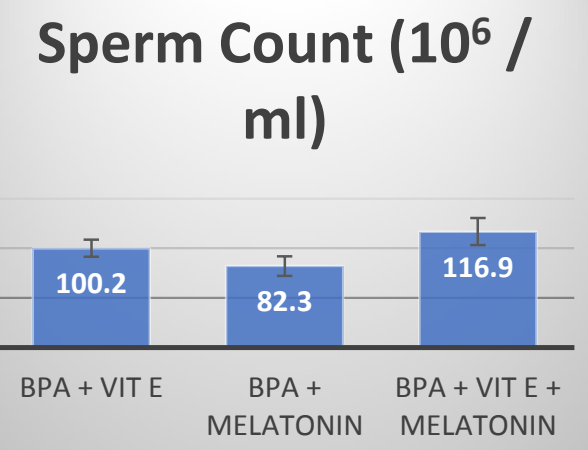

Figure 4. Mean effect of different antioxidants on albino rats' sperm count

\section{Serum Testosterone (ng / dl)}

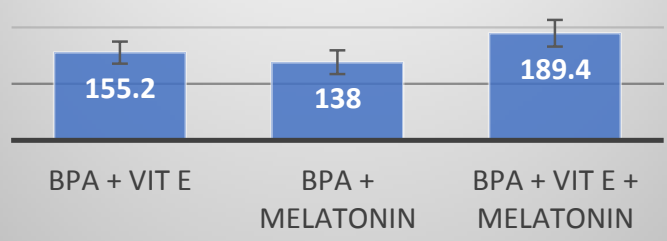

Figure 6. Mean effect of different antioxidants on albino rats' serum testosterone level

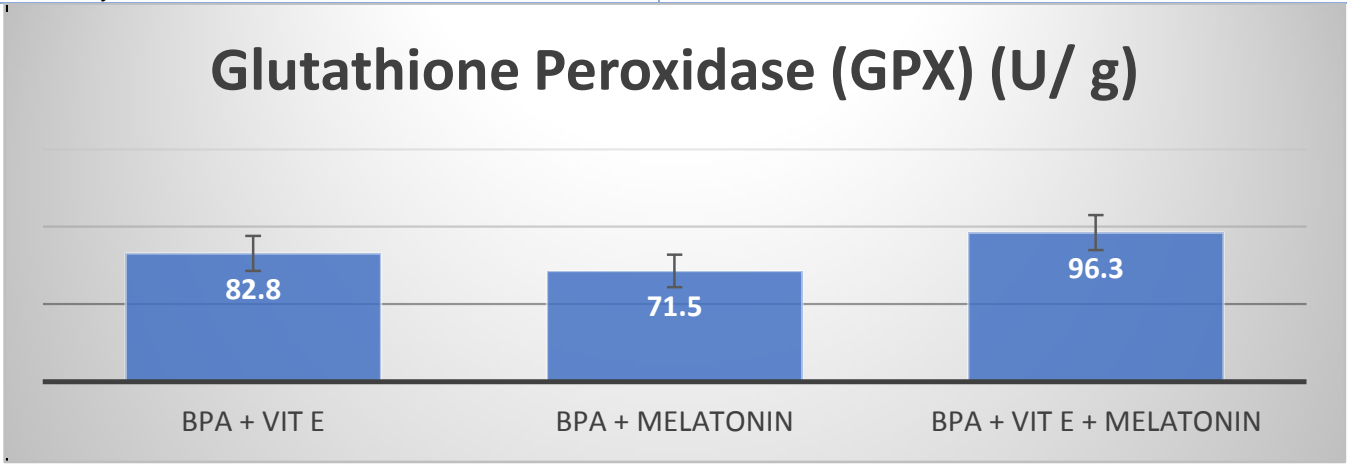

Figure 7. Mean effect of different antioxidants on albino rats' Glutathione Peroxidase (GPX) level. 


\section{DISCUSSION}

It has been documented that bisphenol A (BPA) causes male reproductive dysfunction and can cause severe estrogenic effects, including changes in serum hormones and testicular lesions (Olukole et al., 2020).

The present results indicate that BPA caused testicular dysfunctions; these results were obtained from biochemical and histopathological studies. Antioxidants have an important role in protecting against BPA induced oxidative stress (Amjad et al., 2020). We focused on the role of vitamin $\mathrm{E}$ and melatonin antioxidants; on BPA-induced testicular oxidative stress.

In the current study, BPA caused a significant reduction in reproductive function parameters assessed by abnormal sperm morphology, sperm count, sperm motility, and serum testosterone level. These findings agree with the reports of some studies (Ahbab et al. 2017; Yang et al., 2019; Zahra et al., 2020) that reported a significant decrease in the testosterone level. Moreover, Testicular function and sperm production can be impaired by a decrease in testosterone concentrations.

Testosterone plays a key role in the initiation and maintenance of spermatogenesis, differentiation of male genital organs, and the production of secondary sexual characteristics. Any factor affecting the viability of Leydig cells and/or interfering with testicular steroidogenesis may cause endocrine regulation of spermatogenesis to be disrupted and impair fertility (Selvaraju et al., 2020).

Tests are considered to be highly sensitive to oxidative stress due to the presence of abundant polyunsaturated fatty acids. To counteract the effects of ROS, the testes contain a high concentration of antioxidant defense systems that prevent cell damage. BPA caused toxic effects to the testicular tissue of exposed rats by decreasing the activity of catalase (CAT) and lowering the level of glutathione (GSH) and elevating the level of (malondialdehyde) MDA (Khalaf et al., 2019).

Bisphenol A may inhibit the growth of Sertoli Cells by concomitantly inducing ROS production, loss of mitochondrial membrane potential, apoptosis, autophagy, and necrosis that provide insight into the underlying mechanisms of BPA toxicity in male reproduction (Zhang et al., 2017). Testosterone levels decrease when low BPA concentrations impair the gene encoding steroidogenic enzymes like StAR, P450scc, 3 $\beta$-HSD, Cyp17a1, Cyp19a1, and 17ß-HSD in Leydig cells (Xu et al., 2020).

Increased production of reactive oxygen species (ROS), mitochondrial dysfunction, intracellular $\mathrm{Ca}^{2+}$ overload, and rat Sertoli cell apoptosis can be caused by high BPA concentrations (Wang et al., 2017). Bisphenol A induced oxidative stress in the rats' testicles as evidenced by decrease glutathione peroxidase activity. These findings were consistent with (Anjum et al. 2011; Ullah et al., 2018) who noticed that the function of antioxidant enzymes was significantly reduced and the levels of reactive oxygen species (ROS) in the testicular tissues were significantly elevated.

The present histopathological findings (after 3 weeks) of the BPA -treated group showed widened lumen of some crossly sectioned seminiferous tubules that were free from spermatozoa, vacuolated epithelium, separated epithelial lining from the basement membrane, and congested blood vessels. The above findings were consistent with the study by Olukole, et al. (2020); Zahra et al. (2020) who reported spermatogenic cell vacuolization, sloughing, and reduction, testicular atrophy with substantial loss of spermatogenesis in most seminiferous tubules. In addition, interstitial bleeding, vacuolated, degenerated, and poorly formed Leydig cells were observed.

Several antioxidant substances have been studied for their protective effects against BPA induced oxidative stress. For instance, Asparagus officinalis extract, cinnamon treatment, $\mathrm{N}$-acetylcysteine, and boron (Acaroz et al., 2019).

Administration of melatonin and vitamin $\mathrm{E}$ antioxidants can protect against BPA induced testicular dysfunction. They improved the reproductive function parameters assessed by sperm count, sperm motility, and serum testosterone level. These findings were in 
agreement with Mehranjani et al (2018) who reported that many toxic effects of Bisphenol A on the testis may be compensated for by vitamin $E$ as a substantial decrease in the total volume of the testis, the volume and diameter of the seminiferous tubule, the thickness of the basement membrane, the sperm count, the spermatocyte and Sertoli cells, the level of serum testosterone and counteract the oxidative stress induced by BPA.

By elevating the levels of superoxide dismutase (SOD), catalase (CAT), and decreased glutathione (GSH) in the blood of BPA-exposed albino rats in vivo, vitamin $\mathrm{E}$ restored the enzymatic antioxidant defenses by scavenging free radicals (Nimisha and Sendhilvadivu, 2018). After administration of vitamin $\mathrm{E}$, the levels of thiobarbituric acid reactive substances (TBARS) in the blood of BPA-exposed rats decreased, suggesting decreased lipid peroxidation (LPO) levels (Avci et al., 2016).

Kumar et al (2021) stated that melatonin is a strong molecule that rescued testicular damage caused by the BPA as evident by disrupted histoarchitecture, increased oxidative stress, inflammation, apoptosis through the modulation of oxidative sensor proteins in the male golden hamster Mesocricetus auratus.

Olukole et al. (2018) recorded that sub-acute oral administration of BPA induced serum testosterone level alterations and induced morphological prostate gland lesions in rats, whereas these results were improved by concomitant treatment with intra-peritoneal melatonin injection.

Melatonin and vitamin E antioxidants administration reduced oxidative stress as evidenced by increased the activity of glutathione peroxidase. This was in agreement with Othman et al (2014) who observed that treatment with melatonin resulted in a substantial decrease in the levels of malondialdehyde (MDA) and $\mathrm{H}_{2} \mathrm{O}_{2}$ and a significant increase in testicular SOD and CAT activity in epididymal sperm in comparison to control rats.

Group treated with melatonin showed moderate interstitial edema and vacuolated epithelial lining. These findings are in conformity with Olukole et al. (2019) who reported that melatonin protects against BPAinduced alterations in the male reproductive system by specifically impacting the antioxidant pathway and by inhibiting necrosis. Concurrent melatonin administration has been able to preserve the interstitial tissue of the testicles.

Vitamin E improved the histological features of the testis. Testicular sections from the group received vitamin $\mathrm{E}$ showing mild interstitial edema, widened lumen of few crossly sectioned seminiferous tubules free from spermatozoa, and vacuolated epithelial lining.

Testicular sections from the group received melatonin+vitamin $\mathrm{E}$ showing an improved histological picture of seminiferous tubules with narrowed interstitial space in between. The administration of combined melatonin and vitamin $\mathrm{E}$ together provide better protection for testicular function than the administration of each one alone. This was confirmed by the significant improvement in reproductive function parameters assessed by sperm count, sperm motility, serum testosterone level, increased glutathione peroxidase activity, and less histopathological testicular damage.

\section{CONCLUSION}

The current study investigates the effects of BPA on the male testicular functions in adult male rats. The results suggest that BPA affects significantly the reproductive function parameters and induced oxidative stress. Cotreatment with antioxidants melatonin and vitamin $\mathrm{E}$ ameliorated the increased level of ROS in testes of rats and improved the reproductive function parameters and the histopathological alterations induced by BPA. Future studies are needed to investigate the molecular mechanisms by which BPA affects reproductive functions and the impact of antioxidants to overcome BPA toxicity.

\section{Declaration of competing interest}

The authors declare that they have no known competing financial interests or personal relationships that could have appeared to influence the work reported in this paper.

This research did not receive any specific grant from funding agencies in the 
public, commercial, or not-for-profit sectors.

\section{REFERENCES}

Acaroz, U., Ince, S., Arslan-Acaroz, D., Gurler, Z., Demirel, H.H., Kucukkurt, I., Eryavuz, A., Kara, R., Nuray Varol, N. and Zhu, K. (2019): Bisphenol-A induced oxidative stress, inflammatory gene expression, and metabolic and histopathological changes in male Wistar albino rats: protective role of boron. Toxicol. Res., 8 (2): 262-269.

Ahbab, M.A., Barlas, N. and Karabulut, G. (2017): The toxicological effects of bisphenol A and octylphenol on the reproductive system of prepubertal male rats. Toxicol. Indust. Health, 33:133-146.

Almeida, S., Raposo, A., Almeida-González, M. and Carrascosa, C. (2018): Bisphenol A: Food Exposure and Impact on Human Health. Comprehensive Reviews in Food Science and Food Safety, 17(6):1503-1517.

Amjad, S., Rahman, M. S. and Pang, M. (2020): Role of antioxidants in alleviating Bisphenol A toxicity. Biomolec., 10 (8): 1105.

Amraoui, W., Adjabi, N., Bououza, F., Boumendjel, M., Taibi, F., Boumendjel, A., Abdennour, C. and Messarah, M. (2018): Modulatory role of selenium and vitamin $\mathrm{E}$, natural antioxidants, against Bisphenol Ainduced oxidative stress in Wistar albino rats. Toxicol Res., 34: 231-239. https://doi.org/10.5487/TR.2018.34.3.231

Anjum, S., Rahman, S., Kaur, M., Ahmad, F., Rashid, H. and Ansari, R. (2011): Melatonin ameliorates bisphenol A-induced biochemical toxicity in testicular mitochondria of mouse. Food Chem. Toxicol., 49: 2849-2854.

Avci, B., Bahadir, A., Tuncel, O.K. and Bilgici, B. (2016): Influence of $\alpha$-tocopherol and $\alpha$-lipoic acid on bisphenol-A induced oxidative damage in liver and ovarian tissue of rats. Toxicol. Ind. Health, 32: 1381-1390.

Benjamin, S., Masai, E., Kamimura, N., Takahashi, K., Anderson, R.C. and Faisal, P.A., (2017): Phthalates impact human health: epidemiological evidences and plausible mechanism of action. J. Hazard Mater, https:// doi. org/ 10.1016 /j.jhazmat. 2017.06.036.

Cen, H., Wang, T., Liu, H., Tian, D. and Zhang, Y. (2020): Melatonin Application Improves Salt Tolerance of Alfalfa (Medicago sativaL.) by Enhancing Antioxidant Capacity. Plants, 9, 220 doi:10.3390/plants9020220.

Chen, H., Jin, S., Guo, J., Kombairaju, P., Biswal,
S. and Zirkin, B.R. (2015): Knockout of the transcription factor Nrf2: Effects on testosterone production by aging mouse Leydig cells. Mol. Cell Endocrinol., 409:113-120. DOI: 10.1016/j.mce.2015.03.013 111.

Fuentes, N and Silveyra, P. (2019): Estrogen receptor signaling mechanisms. Adv. Protein Chem. Struct. Biol., 116:135-170. DOI: 10.1016/bs.apcsb.2019.01.001.

Gunata, M., Parlakpinar, H. and Acet, H.A. (2020): Melatonin: A review of its potential functions and effects on neurological diseases. Rev. Neurol., 176 (3): 148-165.

Gulcin, I. (2020): Antioxidants and antioxidant methods: an updated overview. Arch. Toxicol., 94: 651-715.

Jalal, N., Surendranath, A.R., Pathak, J.L., Yu, S. and Chung, C. Y. (2018): Bisphenol A (BPA) the mighty and the mutagenic. Toxicol Rep., 5: 76-84.

DOI: 10.1016/j.toxrep.2017.12.013

Kang, J.H., Kondo, F. and Katayama, Y. (2006): Human exposure to bisphenol A. Toxicol., 226:79-89. DOI: 10.1016/j.tox.2006.06.009

Khalaf, A.A., Ahmed, W.M.S., Moselhy, W.A., Abdel-Halim, B.R. and Ibrahim, M.A. (2019): Protective effects of selenium and nano-selenium on bisphenol-induced reproductive toxicity in male rats. Human Exp. Toxicol., 38(4): 398-408. DOI: $10.1177 / 0960327118816134$.

Kumar, J., Rakesh Verma, R. and Haldar, C. (2021): Melatonin ameliorates Bisphenol $S$ induced testicular damages by modulating Nrf2/HO-1 and SIRT-1/FOXO-1 expressions. Environ. Toxicol., 36:396-407. DOI: 10.1002/tox. 23045

Kurutas, E.B. (2016): The importance of antioxidants which play the role in cellular response against oxidative/nitrosative stress: current state. Nutr J. 15: 71. DOI: 10.1186/s12937-016-0186-5.

Lehmler, H., Liu, B., Gadogbe, M. and Bao, W. (2018): Exposure to Bisphenol A, Bisphenol F, and Bisphenol $\mathrm{S}$ in U.S. Adults and Children: The National Health and Nutrition Examination Survey 2013-2014. ACS Omega, 3 (6): 65236532. DOI: $10.1021 /$ acsomega.8b00824

Li, X., Wen, Z., Wang, Y., Mo, J., Zhong, Y. and Ge, R.S. (2020): Bisphenols and Leydig cell development and function. Front. Endocrinol., 11:447. DOI: 10.3389/fendo.2020.00447

Liu, X.X., Wang, Z.X. and Liu, F.J. (2021): Chronic exposure of BPA impairs male germ cell 
proliferation and induces lower sperm quality in male mice. Chemosphere, 262: 127880.

Mehranjani M, S., Mahmoodi, M. and Amjadi, M. (2018.): Protective role of vitamin $E$ in preventing the adverse effects of bisphenol A on rat testis tissue: A stereological evaluation. JSSU, $26(2): 97-110$.

Niki, E. (2014): Role of vitamin E as a lipid-soluble peroxyl radical scavenger: in vitro and in vivo evidence, Free Radical. Biol. Med., 66: 3-12

Nimisha, B. and Sendhilvadivu, M. (2018): Vitamin E modulates the oxidant-antioxidant imbalance of BPA induced oxidative stress in albino rats. Int. J. Sci. Res., 7:900-906.

Nur, M. I., Widyarti, S. and Sumitro, S. B. (2019): The study of UV spectrum in interaction Astaxanthin and Glycated Bovine Serum Albumin (Gly-BSA). JEEST, 6 (1): 23-29.

Olea-Herrero, N., Arenas, M.I., Muñóz-Moreno, C., Gómez-Toledano, R.M., GonzálezSantander, M., Arribas, I. and Bosch, R.J. (2014): Bisphenol-A induces podocytopathy with proteinuria in mice. J. cell. Physiol., 229 (12): 2057-2066

Olukole, S.G., Ajani, S.O., Ola-Davies, E.O. Lanipekun, D.O., Aina, O.O., Oyeyemi, M.O. and Olusijioke, B. (2018): Melatonin ameliorates bisphenol A-induced perturbations of the prostate gland of adult Wistar rats. Biomed. Pharmacother., 105:73-82. https://doi.org/10.1016/j.biopha.2018.05.125.

Olukole, S.G., Lanipekun, D.O. Ola-Davies, E.O. and Olusijioke, B. (2019): Maternal exposure to environmentally relevant doses of bisphenol A causes reproductive dysfunction in $\mathrm{F} 1$ adult male rats: protective role of melatonin. Environ. Sci. Pollut. Res., 26: 28940-28950. https://doi.org/10.1007/s11356-019-06153-3

Olukole, S.G., Ola-Davies, E.O., Lanipekun, D.O. and Olusijioke, B. (2020): Chronic exposure of adult male Wistar rats to bisphenol A causes testicular oxidative stress: Role of gallic acid. Endocr. Reg., 54 (1): 14-21. doi:10.2478/enr2020-0003

Othman, A., Edrees, G. M., El-Missiry, M. A., Ali, D. A., Aboel-Nour, M. and Dabdoub, B. R. (2014): Melatonin controlled apoptosis and protected the testes and sperm quality against bisphenol A-induced oxidative toxicity. Toxicol. Indust. Health, 1-13. DOI: 10.1177/0748233714561286.

Paglia, D. E. and Valentine, W. N. (1967): Studies on the quantitative and qualitative characterization of erythrocyte glutathione peroxidase. J. Lab. Clin. Med., 70 (1): 158-169.

Pallotti, F., Pelloni, M., Gianfrilli, D., Andrea Lenzi, A. Lombardo, F. and Paoli, D. (2020): Mechanisms of Testicular Disruption from Exposure to Bisphenol A and Phtalates. J. Clin. Med. $\quad 9 \quad$ (2): $\quad 471$. https://doi.org/10.3390/jcm9020471

Pan, D., Feng, D., Ding, H., Zheng, X., Ma, Z., Yang, B., Xie, M., (2020): Effects of bisphenol A exposure on DNA integrity and protamination of mouse spermatozoa. Androl., 8, 486e496.

Rahman, S., Kwon, W.S., Karmakar, P.C., Yoon, S.J., Ryu, B.Y. and Pang, M.G. (2016): Gestational exposure to Bisphenol A affects the function and proteome profile of F1 spermatozoa in adult mice. Environ. Health Perspect., 125: 238-245.

Rahman, S and Pang, M.G. (2019): Understanding the molecular mechanisms of bisphenol A action in spermatozoa. Clin. Exp. Reprod. Med., 46 (3): 99-106.

Ratliff, B.B., Wasan Abdulmahdi, W., Pawar, R. and Wolin M.S. (2016): Oxidant mechanisms in renal injury and disease. Antioxid. Redox Signal., 25 (3): 119-146. DOI: 10.1089/ars.2016.6665

Reiter, R. J., Tan, D. and Galano, A. (2014): Melatonin reduces lipid peroxidation and membrane viscosity. Front. Physiol., 5: 377. DOI: 10.3389/fphys.2014.00377.

Selvaraju, V., Baskaran, S., Agarwal, A. and Ralf Henkel, R. (2020): Environmental contaminants and male infertility: Effects and mechanisms. Androl., $\quad 53 \quad$ (1): $\quad 1-13$. https://doi.org/10.1111/and.13646.

Shanle, E.K. and Xu, W. (2011): Endocrine disrupting chemicals targeting estrogen receptor signaling: identification and mechanisms of action. Chem. Res. Toxicol., 24 (1):6-19. $\quad$ DOI: 10.1021/tx100231n.

Sönmez, M., Türk, G. and Yüce A. (2005): The effect of ascorbic acid supplementation on sperm quality, lipid peroxidation and testosterone levels of male Wistar rats. Theriogenol., 63: 2063-2072

Tavakkoli, A., Abnous, K., Hassani, F.V., Hosseinzadeh, H., Birner-Gruenberger, R. and Mehri, S. (2020): Alteration of protein profile in cerebral cortex of rats exposed to bisphenol A: A proteomics study. Neuro.Toxicol., 78: 1-10.

Ullah, A., Pirzada, M., Jahan S., Ullah H., Shaheen, G. and Rehman, H. (2018): Bisphenol $\mathrm{A}$ and its analogs bisphenol $\mathrm{B}$, bisphenol $\mathrm{F}$, and bisphenol $\mathrm{S}$ : Comparative in vitro and in vivo 
studies on the sperms and testicular tissues of rats. Chemosphere, 209:508-16. DOI: 10.1016/j.chemosphere.2018.06.089

Wang, C., Qi, S., Liu, C., Yang, A., Fu, W., Quan, C., Duan, P., Yu, T. and Yang, K. (2017): Mitochondrial dysfunction and $\mathrm{Ca}^{2+}$ Overload in injured Sertoli cells exposed to Bisphenol A. Environ. Toxicol., 32: 823-831. https://doi.org/10.1002/tox.22282.

Wilson, N.K., Chuang, J.C., Lyu, C., Menton, R. and Morgan, M.K. (2003): Aggregate exposures of nine preschool children to persistent organic pollutants at daycare and at home. J. Expo. Anal. Environ. Epidemiol., 13:187-202. DOI: 10.1038/sj.jea.7500270

Xu, A., Li, X., Li, K., Zhang, J., Li, Y., Gong, D., Zhao, G., Zheng, Q., Yuan, M., Lin, P. and Huang, L. (2020): Linoleic acid promotes testosterone production by activating Leydig cell GPR120/ ERK pathway and restores BPAimpaired testicular toxicity, Steroids. DOI: $\quad$ https://doi.org/10.1016/j.steroids.
Yang, Q., Sui, X., Cao, J., Liu, C., Zheng, S., Bao, M., Huang, Y. and Wu, K. (2019): Effects of exposure to bisphenol A during pregnancy on the pup testis function. Internet $J$. Endocrinol., 6785289:2019.

Zahra, Z., Khan, M.R., Majid, M., Maryam, S. and Sajid, M. (2020): Gonadoprotective ability of Vincetoxicum arnottianum extract against bisphenol A-induced testicular toxicity and hormonal imbalance in male Sprague Dawley rats. Androl., 52 (6): e13590.

Zhang, Y., Han, L., Yang, H., Pang, J., Li, P., Zhang, G., Li, F and Wang, F. (2017): Bisphenol A affects cell viability involved in autophagy and apoptosis in goat testis Sertoli cell. Environ. Toxicol. Pharmacol., 137-147. DOI: http:// dx. doi. org/ doi: 10.1016/j.etap.2017.07.014 